\title{
A MIGRAÇÃO VENEZUELANA EM BELÉM DO PARÁ E O PAPEL INSTITUCIONAL DO ESTADO NA SUA ORGANIZAÇÃO
}

\author{
Dexter André Santos da GAMA ${ }^{1}$ \\ Israel Esteban Muñoz da COSTA ${ }^{2}$
}

\section{RESUMO}

O presente trabalho trata-se do levantamento bibliográfico sobre a migração venezuelana, a qual será expandida para um trabalho de conclusão de curso futuramente. Objetiva-se compreender como ocorre o processo de migração para a cidade de Belém (PA), afim de entender as particularidades deste desde a elucidação dos sujeitos, suas aspirações e o papel do Estado em relação a este processo. Foi analisada a trajetória da legislação na escala global e nacional existente de forma mais geral, além de conhecer por meio de aproximação com a realidade os principais desafios de se migrar para a capital do Pará. Através da utilização de entrevistas com os agentes institucionais envolvidos nesse processo e com os migrantes venezuelanos, possibilitou-se uma aproximação a esse fenômeno migratório ao se analisar a práxis institucional em relação à realidade social. Destaca-se que, embora importantes, as medidas tomadas pelo estado do Pará ainda são insuficientes devido à falta do trabalho conjunto de diferentes esferas do poder, de uma política nacional do imigrante, e da intensidade do fluxo migratório.

Palavras-Chave: Migração, Venezuela, Belém, Estado, Leis.

\section{ABSTRACT}

This present study is a bibliographical survey on the subject of Venezuelan migration, which will be expanded to a end-of- course paper in the future. The objective of this study is to understand how the process of migration to the city of Belém (PA) occurs, in order to understand the particularities of this process ranging from the elucidation of the subjects, their aspirations and the role of the State regarding this process. We carried out a general analysis of the existing legislation and its trajectory on a global and national scale, besides getting to know, through close contact with the current reality, the main challenges connected to migrating to the capital of Pará. Through interviews with the institutional agents involved in this process and with the Venezuelan migrants, we were able to approach this migratory phenomenon through analyzing the institutional praxis and its relation to the social reality. It should be highlighted that, although important, the measures taken by the state of Pará are still insufficient due to the lack of joint work from different spheres of power, the absence of a national policy for immigrants, and due to the intensity of the migratory flow.

Key-Words: Migration, Venezuela, Belém, State, Laws.

\footnotetext{
${ }^{1}$ Graduando do curso de licenciatura em Geografia - IFPA. E-mail: dexgama22@gmail.com

${ }^{2}$ Graduando do curso de licenciatura em Geografia - IFPA. E-mail: israel.geografia16@bol.com.br
} 


\section{Dexter André Santos da GAMA; Israel Esteban Muñoz da COSTA}

\section{INTRODUÇÃO}

Os grandes movimentos de massas humanas, tanto influenciadas por elementos físico-naturais quanto políticos, sempre fizeram parte da dinâmica social na constituição do território. O Brasil, em suas dimensões continentais, o qual desponta na América Latina como um país em desenvolvimento, constitui uma zona atrativa para os imigrantes. Segundo a International Organization for Migration (IOM), em seu World Migration Report $2013^{3}$, existem mais de 230 milhões de pessoas vivendo em países diferentes do seu país de origem, os quais cerca de $40 \%$ dessas pessoas, diferente do que se concebia há pouco, migram para países em desenvolvimento.Nota-se que a América do Sul, como um todo, vive um grande processo de instabilidade política e crise política, econômica e humanitária, resultando no aumento do fluxo migratório da Venezuela para o Brasil. Nesta perspectiva, é preciso entender como este país, enquanto zona atrativa para migrantes, ordena institucionalmente esse fluxo. Por opção metodológica, trouxemos a discussão sobre a migração venezuelana para uma escala local, a capital do estado do Pará, Belém, afim de entender quais elementos tornam esse processo particular. Neste artigo será brevemente exposto como ocorre o processo de migração de refugiados venezuelanos para Belém através de uma análise de políticas institucionais do poder público em relação a esses sujeitos. Será discutida a trajetória da legislação que trata das migrações em escala global, a partir do documento Diretrizes da Alto Comissariado das Nações Unidas para os Refugiados (ACNUR), e nacional no que se refere ao imigrante, além de conhecer por meio de aproximação com a realidade os principais desafios de se migrar da Venezuela para a cidade de Belém (PA).

Objetiva-se, com isso, compreender como ocorre o processo de migração para uma cidade como Belém do Pará para entender as particularidades desse processo migratório desde a elucidação dos sujeitos, suas aspirações e o papel do Estado em relação a este processo. Cabe também analisar a trajetória da legislação na escala global e nacional existente de forma mais geral, além de conhecer por meio de aproximação com a realidade os principais desafios de se migrar para Belém (PA).

\footnotetext{
${ }^{3}$ Disponível em: https://publications.iom.int/system/files/pdf/wmr2013_en.pdf $>>$ acesso em 31/07/2018 às 17:27 PM.
} 


\section{Dexter André Santos da GAMA; Israel Esteban Muñoz da COSTA}

A abordagem metodológica sobre este tema se fundou na pesquisa bibliográfica sobre o assunto a ser tratado, haja vista que a migração é um objeto de pesquisa abordado por diferentes ciências.Com isso, era necessário que se aproximasse de suas várias facetas para buscar geografizá-las. Além disso, baseou-se em pesquisas às legislações internacionais e nacionais em relação ao migrante. Também foram realizadas entrevistas com agentes institucionais envolvidos e os próprios refugiados venezuelanos nas casas de passagem subsidiária da SEASTER e SEJUDH foram importantes à pesquisa de modo a comparar as ações previstas em lei com a ação institucional de fato, bem como conhecer o sujeito - migrante venezuelano- enquanto pessoa a qual afetam estes processos.

\section{UMA BREVE ABORDAGEM TEÓRICA SOBRE MIGRAÇÃO}

A migração é um dos fenômenos humanos mais antigos e recorrentes que existem, sendo determinada por diversos fatores e ocorrendo em diversas épocas da história (XAVIER, 2012). Kivisto \& Faist, (p. 1) apud Xavier, (p. 23) concebe a migração como o movimento de pessoas para além das fronteiras nacionais. Nota-se uma limitação deste conceito em face da complexidade desse fenômeno. Há que se analisar o fenômeno através das "múltiplas dimensões da migração" (CASTIGLIONI, 2009, p.39). As causas podem ser variadas, com motivações sociais (desde à esfera pessoal até a esfera comunitária, reflexo de condições sócio-políticas e econômicas) ou razões físico-naturais alheias a seu controle, tais quais fenômenos da natureza. Como exemplo de migração causada por fatores naturais, temos a Grande Seca de 1915 no Ceará, a qual um período de estiagem intenso e conseqüente insuficiência na produção de alimento de pequenos produtores rurais motivou o êxodo de um grande contingente de pessoas para a capital Fortaleza e outros estados da região nordeste. Como exemplo de migração causada por fatores sócio-políticas tem-se a grande migração de peruanos e venezuelanos para a Amazônia Legal brasileira, por falta de oportunidades laborais e perspectivas econômicas em seus países. Ainda pode-se destacar a ação do Estado como fomentador de movimentos migratórios de acordo com suas demandas, quase sempre 


\title{
Dexter André Santos da GAMA; Israel Esteban Muñoz da COSTA
}

relativas ao ordenamento territorial, como povoamento regional, integração entre regiões, estimulo a um circuito comercial local.

\begin{abstract}
As políticas estatais de fomento à produção de borracha, por exemplo, foram no Brasil iniciativas que colocaram em destaque as migrações e a promoção da ocupação da região amazônica, ao mesmo tempo que buscavam esvaziar tensões sócias na região Nordeste [...] Posteriormente, as ditas políticas de integração nacional, durante o regime militar, bem como de estímulo à colonização agrícola e à garimpagem, nesse período, têm um componente quase sempre explícito de intervenção quanto às migrações para a Amazônia. (NETO, 2013, p, 290-291)
\end{abstract}

Como exemplo, tem-se o Estado Varguista que, de acordo com demandas geopolíticas - A segunda guerra mundial - pautado na necessidade sobre a borracha, matéria prima largamente produzida pelo Brasil na época, teve necessidade em estimular um grande movimento migratório interno em direção ao norte através do Serviço Especial de Trabalhadores para a Amazônia (SEMTA) em 1943 e, pouco mais de vinte anos depois, um governo de regime militar que tornou-se o principal interventor na produção de espaço na região amazônica por diversos motivos: integrar a região amazônica ao resto do país, criar um exército de reserva de trabalhadores, criar um mercado de consumo industrializado e nacional (GONÇALVES, 2005).

Vê-se, então, o fenômeno da migração sendo condicionado à fatores externos à população que migra, ou seja, "a migração é um fenômeno reflexo [...] O fenômeno representa uma resposta da população ao processo de mudanças socioeconômicas que opera em um contexto específico durante um determinado tempo". (CASTIGLIONI, 2009, p.40). Assim, também é uma possibilidade do Estado, como interventor e produtor do espaço, de mitigar demandas territoriais e econômicas, justificando a importância de discutir seus mecanismos a partir de políticas migratórias e de sua legislatura em relação ao migrante. É necessário, além disso, expor que o processo migratório é multifacetado, isto é, sua motivação e condições de acontecimento estão sujeitos à uma gama de elementos variada e um riquíssimo objeto de estudo, que passou a ser partilhado pela geografia, demografia, sociologia, ciência, política, historiografia e ciências afins (GOMES, 2005 apud XAVIER, 2012) denotando que a formulação de 
uma teoria geral da migração é um objetivo impossível (PEIXOTO, 2004 apud JANSEN, 1969, p. 04).

Considerando o exposto, podemos conceber a migração venezuelana de acordo com as suas causas a nível de política internacional - crise humanitária, política, econômica derivada da queda do preço do barril do petróleo e o embate político do governo de Nicolás Maduro e a oposição de orientação neoliberal, aliada ao interesse do capital estrangeiro - e a nível pessoal ou individual - aspirações profissionais a qual não poderiam ser atingidas devido ao contexto sociopolítico venezuelano desde 2014, necessidade de sobrevivência e a fuga da fome e a miséria presente na Venezuela causando o processo migratório de venezuelanos. Castiglioni (2009) tenta considerar vários níveis de compreensão da dinâmica da migração ao entender que as motivações para migração, sendo os determinantes econômicos apenas uma destas motivações. No caso da Venezuela, o determinante econômico tem um peso considerável, visto que ele influencia diretamente sobre as questões sociais.

A migração venezuelana, de fato, tem como destino o Brasil, um país em desenvolvimento, entre as dez maiores economias do mundo, e de importância regional em relação a seus vizinhos latinos tanto pela sua extensão territorial quanto pela sua importância econômica e política na América do Sul. Pode-se ler essa dinâmica migracional através da teoria de Everett Lee e sua relação entre os espaços de atração e repulsão:

\footnotetext{
a migração resulta de uma resposta dada pelos indivíduos a dois conjuntos de forças: os fatores pessoais, que atuam em um nível micro, e os fatores estruturais, que compreendem estímulos econômicos, políticos e sociais. As regiões de origem e de destino possuem uma série de fatores positivos, negativos e neutros que atraem, empurram ou deixam as pessoas indiferentes. Esse conjunto de fatores estimula o indivíduo a deixar um lugar (push factor) ou atraí-lo para outro (pullfactor) (CASTIGLIONI, 2009, p. 44).
}

Desta forma, o Brasil seria a região de pull fator a qual atrai esse contingente populacional, em busca de melhores condições de vida, devido a melhores oportunidades e infraestrutura que o país oferece, enquanto a Venezuela se caracterizaria como uma região de push factor, que repele as pessoas que vivem nela, por falta de oportunidades laborais, falta de alimento e até mesmo, negação de direitos humanitários. Pode-se entender essa dinâmica migracional também através da teoria do 
sistema-mundo de Wallerstein (1979)apud Castiglioni (2009)entre as relações de polarização entre Central x Periférico.

\begin{abstract}
polarização entre centralidade e perifericidade. As nações estão classificadas em: região central, que dispõe do poder dominante, regiões semiperiféricas, muito ligadas ao centro, mas providas de certa autonomia; e regiões periféricas, as que têm pouco poder. Os mecanismos subjacentes a esses sistemas - forte, intermediário e fraco - levam à criação de excedentes de mão-de-obra e baixos salários nas periferias, a qual contrasta com a oferta de salários elevados nos países do "centro" (CASTIGLIONI, 2009, p.50).
\end{abstract}

Então, entenderíamos que a nível reduzido de análise - pelo menos em relação a uma escala global, e mais expandido que uma escala regional - o Brasil seria a região central dentro da América do Sul, sendo alvo da migração de países periféricos como Venezuela, Peru, Bolívia, sendo possível notar a presença destes na Região Norte do Brasil, na Amazônia Legal.

\title{
3. O PERFIL DO MIGRANTE VENEZUELANO
}

Foi notado após as pesquisas de campo e estudos de relatórios institucionais que há pelo menos dois perfis diferentes entre os migrantes venezuelano e que pode ser observado no Pará em uma proporção desigual, uma vez que os migrantes venezuelanos são em maioria indígena $W \operatorname{rao}^{4}$ e o restante, não-indígena. Esses dois perfis são considerados, nessa pesquisa, a partir da sua posição social enquanto sujeito inserido numa sociedade capitalista. Esse foco de análise permite crer a instrução e formação laboral, profissional, acadêmica e formal influenciem as aspirações à destino dos migrantes.

Em sua maioria, os indígenas Warao encontram na Região Norte um espaço onde há mais possibilidade de inserção social, uma vez que sua trajetória comunitáriaindividual e cultural não coaduna com o perfil do labor formal e especializado do modo de trabalho capitalista que é seletivo, portanto, excludente. Os indígenas Warao que

\footnotetext{
${ }^{4}$ Os Waraos são uma etnia indígena venezuelana que ocupam os canais do Delta do Orinoco. Estão adaptados à vida em harmonia com o rio, vivendo em palafitas construídas em ilhas sedimentares alagáveis, vivendo da pesca e da caça e coleta. Disponível em http://panoramacultural.com.br/indioswaraol.> acesso em 31/07/18 as 17:58.
} 


\section{Dexter André Santos da GAMA; Israel Esteban Muñoz da COSTA}

foram entrevistados em Belém dizem que querem ficar e trabalhar, e viver da renda desse trabalho, que são os trabalhos "sencillos", e "lasartesanias" (trabalhos manuais e artesanais) que foram aprendidos na sua vida comunitária e são representantes da sua historicidade enquanto indígenas.

O outro perfil de migrante venezuelano -o não-indígena- apresenta-se como um sujeito de formação laboral diversificada e madura a qual não concebe seu país de residência um promotor de condições mínimas de sobrevivência, cabendo a ele, fugir a outros países. Geralmente, são pessoas que ainda têm família na Venezuela, que almejam se inserir no circuito formal do mercado de trabalho, que têm uma quantia de dinheiro para viajar e sobreviver no seu percurso até o destino final. Esses migrantes, em sua maioria, vêem o Pará como ponto de passagem para as Regiões Sul e Sudeste, sendo acolhidos em casa de passagens. Entretanto, sua condição de estrangeiro - que fala outra língua, tem outra cultura e outros costumes, bem como desconhece a dinâmica urbana onde está presente - o coloca em condição de risco, não sendo rara os casos de migrantes venezuelanos não indígenas (e também os indígenas) que são assaltados, sofrem algum tipo de assédio e violência pela população que vive nas cidades onde o migrante está. Isto aumenta o tempo de estadia no lugar, onde o migrante antes via como passagem, agora se fixa e tenta "ganar el dinero" e ir para seu destino primeiro, como disse o venezuelano Carlos que trabalhava como supervisor no controle de qualidade numa indústria do ramo de alimentos na Venezuela, e, ao chegar no Pará, teve extraviado todo seu dinheiro que serviria para migrar à Região Sudeste. No estado do Pará há a predominância do perfil do migrante venezuelano da etnia Warao, observado na casa de passagem Domingos Salim Jacob Zahluthonde de 119 pessoas que lá residem temporariamente, 118 são da etnia Warao.

\section{A TRAJETÓRIA DA LEGISLAÇÃo SOBRE O MIGRANTE NA ESCALA INTERNACIONAL E NACIONAL}

A partir de 1948, com a Declaração Universal dos Direitos Humanos, a figura do migrante ou refugiado passa a ter um olhar especial nos acordos multilaterais, em virtude das consequências traumáticas da Segunda Guerra 


\section{Dexter André Santos da GAMA; Israel Esteban Muñoz da COSTA}

Mundial. Após a Declaração dos Direitos Humanos, outros documentos são elaborados no intuito de melhorar minimamente as condições das pessoas que se deslocavam entre as nações.Entre eles, podemos citar o pacto internacional de direitos civis e políticos em 1966 e a convenção internacional para a proteção dos Direitos Humanos no ano de 1979.

Em 1990 é aprovado e assinado o primeiro texto onde realmente os Estados se comprometiam politicamente em aplicar conforme a legislação vigente as diversas prerrogativas inerentes aos migrantes. Nesse sentido, conforme Campos e Silva (2015), o principal objetivo dessa Convenção era o de, mesmo com algumas contradições, garantir a todos os trabalhadores migrantes e suas famílias o mínimo acesso a direitos, sendo irrelevante ao tratado a condição que ocorreu seu deslocamento.

Contudo, ainda de acordo com Campos e Silva (2015), mesmo depois de aprovado, o texto só entrou em vigor no ano de 2003, acarretando em um hiato de medidas e políticas públicas dos países para essas pessoas durante estes treze anos. A grande novidade desse texto era de a obrigatoriedade dos países signatários em inserir em forma de emenda constitucional, os direitos e deveres da pessoa migrante.Tal exigência teve como consequência uma baixa adesão dos Estados nacionais, tendo somente 47 países ratificando o acordo, sendo inclusive o Brasil um desses poucos adotantes, todavia, o país nesse período ainda não havia adicionado o texto em forma de emenda à constituição. A hesitação da maioria das nações em relação à imigração coincide com uma "obrigação" de proteger fronteiras em detrimento da entrada de estrangeiros com o subterfúgio da proteção da soberania nacional.

No Brasil, a regulação devido à questão migratória se deu ainda no século XIX, durante o início da república, devido ao incentivo a entrada de europeus para trabalharem na agricultura. Nesse sentido, percebe-se um Estado que fomenta a migração de povos considerados bem vindos a recém-constituída pátria, na medida em que, além da necessidade de mão de obra um pouco mais qualificada em relação aos escravizados de origem africana para trabalharem em um momento do processo produtivo já impactado pela revolução industrial, o governo brasileiro desejava mudar radicalmente as características físicas de sua população que era basicamente constituída de negros e indígenas, para um tom mais claro de pele tendo tal prática ficado conhecida 


\section{Dexter André Santos da GAMA; Israel Esteban Muñoz da COSTA}

como "branqueamento" da raça brasileira conceito sociobiológico utilizado por Schwarcz (1993).

O segundo momento da análise sobre o percurso da legislação se dá no século XX, já no período compreendido entre o Estado novo com Getúlio Vargas (1930-1945) até o momento histórico que compreende os anos de 1964 a 1985, o regime militar. Esse recorte histórico é marcado pela grande hostilidade e aversão por parte do governo brasileiro a entrada e permanência de imigrantes no país.Tal política essencialmente nacionalista reflete as características ditatoriais que marcaram os mais de vinte dos governos militares no Brasil. Durante a gestão militar, uma série de barreiras da legislação praticamente inviabilizavam o ingresso e permanência dos migrantes, com destaque à lei $\mathrm{n}^{\circ} 6.815$ de 1980, conhecida como estatuto do estrangeiro. Esta impunha uma gama de restrições à permanência a "não nacionais" - o termo utilizado pelos generais que comandavam a nação - entre as restrições é possível destacar três dispositivos que indicavam claramente politica antiestrangeiro:

1) a inexistência de qualquer capítulo destinado a explicitar garantias jurídicas e direitos cuja titularidade seja reconhecida às pessoas de outras nacionalidades, ou até mesmo uma definição formal que caracterize o status pessoal dentro do regime geral de permanência migratória no país; 2) um rol de vedações que se estende a limitações profissionais, produtivas, sociais e políticas, e; 3) um status de precariedade e invisibilização que alcança especialmente os imigrantes indocumentados. (Campos e Silva, 2015, p.56)

Ainda nacionalmente, no ano de 2009 é aprovada a lei $\mathrm{n}^{\circ} 5.655$, que entre outros aspectos, previa modificações sensíveis à questão migratória especialmente no seu artigo $4^{\circ}$ o qual prevê aos migrantes as prerrogativas de admissão de mão-de-obra especializada adequada aos vários setores da economia nacional, ao desenvolvimento econômico, social cultural, científico e tecnológico do Brasil, à captação de recursos e geração de emprego e renda, observada a proteção ao trabalhador nacional, entre outros dispositivos ${ }^{5}$.Ainda em 2009, também é aprovada o decreto $\mathrm{n}^{\circ} 6.975$ que tratava sobre a residência de pessoas que fizessem parte dos países que compunham o Mercado Comum do Sul (MERCOSUL) como Brasil, Argentina, Bolívia, Paraguai, Uruguai,

\footnotetext{
${ }^{5}$ Para informações sobre esse projeto de lei, consulte:

http://www.camara.gov.br/proposicoesWeb/fichadetramitacao?idProposicao=443102. Acesso em: 05agosto 2018. 
Dexter André Santos da GAMA; Israel Esteban Muñoz da COSTA

Equador, Colômbia, Venezuela e Peru, o acordo ensejava igualmente a livre circulação de cidadãos portando documento de identificação oficial nesses mesmos países.

\section{AS AÇÕES INSTITUCIONAIS RELACIONADAS AO RECENTE FLUXO MIGRATÓRIO VENEZUELANO EM BELÉM DO PARÁ}

Percebeu-se que o estado do Pará, por meio de suas secretarias, SEASTER e SEJUDH, têm unido esforços a fim de dar dignidade e cidadania aos migrantes, ao atuar da seguinte forma: retira os migrantes das ruas da cidade e os levar para abrigos provisórios, onde são prestados atendimentos de saúde posteriormente alimentados;verificam sua documentação de entrada no Brasil e os que apresentam alguma pendência são encaminhados a Policia Federal ${ }^{6}$; tentar inserir os migrantes no mercado formal de trabalho e emprego.

Esta ação, no entanto encontra principais dificuldades que se estabelecem neste momento: a) crise econômica pela qual o Brasil vem passando, fato que impulsionou um aumento do índice de desemprego; b) ao baixo nível de escolaridade apresentado pelos venezuelanos.Segundo apurado pelo relatório da socióloga Selli Rosa, a SEASTER tem promovido por meio de oficinas de artesanato - as quais os waraos têm certa facilidade - como forma inicial de inseri-los na economia local para que tenham algum tipo de renda. Este é justamente um dos maiores anseios identificados durante as entrevistas com alguns membros e o líder da referida etnia Warao.

Tal súbita demanda tem exigido do estado do Pará ações a curto e médio prazo, na busca por mitigar tamanha questão humanitária. Entre elas, tratou-se da criação de um Posto Avançado de Atendimento Humanizado ao migrante (PAAHM), vinculado à própria SEJUDH e localizado no aeroporto internacional de Belém.Em entrevista com Selli Rosa, percebeu-se queo grande objetivo deste é "prestar atendimento humanizado aos brasileiros que estejam regressando ao país e estrangeiros que por ventura tenham tido seu pedido de permanência negado e por isso estejam sendo deportados (...) o posto se propõem igualmente a mapear e auxiliar de maneira especifica as vitimas de tráfico

\footnotetext{
${ }^{6}$ Caso não tenham nenhuma divergência, os adultos recebem um termo de permanência provisório enquanto os processos de refúgio são analisados pela justiça brasileira.
} 


\section{Dexter André Santos da GAMA; Israel Esteban Muñoz da COSTA}

de pessoas, tendo em vista a implantação de uma política pública em conjunto com o poder público local".

Outra importante ação observada em nossa pesquisa foi a criação de uma casa de passagem/acolhimento. A casa de passagem é destinada a receber no máximo de 50 (cinqüenta) pessoas, caracteriza-se pela oferta de acolhimento imediato e emergencial, distingue-se por ter um fluxo mais rápido, uma vez que recebe indivíduos em trânsito, com uma permanência máxima de 90 dias $^{7}$, e a pesquisada em Belém consiste numa unidade de atendimento ao imigrante em trânsito coordenada pela SEASTER localizada no bairro do Marco em Belém, chamada Domingos Salim Jacob Zahluth. Esse local, como se pode perceber nas duas visitas feitas, trata-se de uma residência alugada para receber provisoriamente os venezuelanos, pois grande parte deles estavam vivendo nas ruas da cidade. Nas cidades as quais estão recebendo grande volume de migrantes, como é o caso da capital paraense, o que se observa, como destacam Pinto e Obregon (2018), é uma verdadeira sobrelotação das como ocorre em Boa vista e Pacaraima no estado de Roraima, problema corriqueiro nas mesmas tendo em vista que mais de 30 mil venezuelanos chegaram a tais cidades em um curto espaço de tempo. Destes, muitos conseguem abrigar-se em locais provisórios, como ginásios e recebem assistência médica e alimentação. Além das indispensáveis assistências mencionadas, vimos também uma preocupação da secretaria por meio da casa de passagem em oferecer letramento na língua portuguesa especialmente às crianças menores, juntamente com cursos profissionalizantes aos adultos que possibilitem a inserção dessas pessoas no mercado de trabalho. Em entrevista o secretário da SEASTER Charles Tuma disse que o Estado está agindo na função de promotor de igualdade social e de condições laborais, ao oferecer aos migrantes indígenas cursos profissionalizantes como: pedreiro, carpinteiro, gerência de pequenos negócios. Nota-se uma intenção de reaproveitar as habilidades desse sujeito, ao transmutar a função desse trabalho artesanal, de representação social e cultural em produtos culturais com a finalidade de comercialização, bem como, a intenção de "inserir esse sujeito no mercado de trabalho e colocá-lo em posição de justa concorrência com os demais brasileiros" a partir da

\footnotetext{
7 Disponível em: http://mds.gov.br/assuntos/assistencia-social/unidades-de-atendimento/unidades-deacolhimento/servico-de-acolhimento-para-adultos-e-familias > >acesso em 31/07/18 as 17:42
} 


\section{Dexter André Santos da GAMA; Israel Esteban Muñoz da COSTA}

profissionalização deles. Como fatores que dificultam a operacionalização desse intento pelo Estado, destacam-se: a linguagem nativa da sua etnia (o espanhol é uma língua que nem todos os indígenas sabem falar) e as necessidades a curto prazo desse migrante, uma vez que a ação institucional se mostra à médio-longo. Observa-se então o modo de ordenamento desse fenômeno pelo Estado a partir da tentativa de inserção desses sujeitos no mercado de trabalho

É nítido que tais ações não são suficientes para suprir tamanha demanda, todavia, podemos considerar o estado do Pará como um bom exemplo de atendimento e acolhimento a essas pessoas, pois se percebe o esforço por parte do governo e suas secretarias em organizar um trabalho coordenado, a fim de oferecer pelo menos o mínimo que tal demanda exige, e o que a legislação internacional e brasileira prevê.

\section{RESULTADOS PRELIMINARES}

Após as pesquisas, percebeu-seque não há uma política nacional consolidada em relação ao migrante, cabendo aos estados criar ações sistemáticas para lidar com esse fenômeno. Compreendeu-se a dinâmica migratória em relação aos territórios - $\mathrm{O}$ Brasil em relação à América do Sul, e a Região Norte em relação às outras regiões do país. Há uma multiplicidade de espaços geográficos satélites no que diz respeito à atração de pessoas, que observado em escala reduzida, mostra-se contraditória.A Região Norte se mostra mais requisitada que a Região Sudeste, em relação aos imigrantes venezuelanos especialmente os de origem indígena. Essa alógica, entre as regiões de destino de migrantes, vimos que está só pode ser compreendida quando mudamos o foco de análise de "Espaço geográfico e desenvolvimento urbano" para os diversos sujeitos envolvidos no processo, e como eles se espacializam de acordo com seu perfil socioeconômico e cultural. Observou-se dois perfis de migrantes venezuelanos no Pará: os indígenas waraos(constituem maioria) e os não indígenas. Na casa de passagem subsidiária da SEASTER, atualmente estão abrigados 119 migrantes, dentre os quais, apenas 1 é não-indígena. As ações institucionais em relação aos migrantes têm como primeiro objetivo a retirada das pessoas das ruas de Belém, oferecendo uma condição mínima de moradia digna, com o intuito de posteriormente inseri-los no mercado de 
Dexter André Santos da GAMA; Israel Esteban Muñoz da COSTA

trabalho e promover, através da profissionalização destes, condições igualitárias de competitividade no mercado.

\section{CONSIDERAÇÕES FINAIS}

Destaca-se que embora importantes essas medidas tomadas pelo estado do Pará, são insuficientes às demandas especialmente socioeconômicas que estão no âmago dessa problemática. Acreditamos como necessárias de acordo com entrevistas com agentes institucionais do estado, medidas como a criação de uma política de acolhimento aos migrantes que envolva as esferas de poder estaduais, municipais e federais, conscientizado também a própria sociedade no trato respeitoso e humanizado para com essas pessoas por meio de simpósios, audiências públicas e reuniões.Nesse sentido acreditamos que a educação por meio das escolas também tem um papel estratégico nesse processo, bem como a mídia na divulgação da dramática situação enfrentada por nossos vizinhos sul-americanos e importância pelo viés dos direitos humanos já destacados neste trabalho, de tratá-los com urbanidade. Para isso, também são urgentes maiores investimentos por parte da União, no auxilio a cidades como Belém a fim de que tenham condições infraestruturais mínimas de receber essas pessoas e criação de programas sociais especialmente de alfabetização quando se refere às crianças.

\section{BIBLIOGRAFIA}

CAMPOS, Bárbara Pincowsca Cardoso; SILVA, João Guilherme Lima Granja Xavier. da. Igualdade, não-discriminação e política para migrações no brasil: antecedentes, desafios e potencialidades para 0 acesso da pessoa migrante a direitos e serviços. Migrações, deslocamentos e direitos humanos, v. 1, p. 50-64, 2015.

CASTIGLIONI, A.H. Migrações: Abordagens Teóricas. In: Migrações internacionais na Pan-Amazônia. Belém. NAEA/UFPA, 2009.

GONÇALVES, Carlos Walter Porto. Amazônia, amazônias. Editora Contexto, 2005.

PASSOS, Cláudio Roberto Farias. Os gêneros de vida na geografia humana. OKARA: Geografia em debate, v. 11, n. 1, p. 120-124, 2017. 
PEIXOTO, João. "As teorias explicativas das migrações: Teorias Micro e Macrosociológicas". Publicação seriada do SOCIUS, Universidade Técnica de Lisboa, Lisboa, 2004.

PINTO, Lara Constantino; OBREGON, Marcelo Fernando Quiroga. A CRISE DOS REFUGIADOS NA VENEZUELA E A RELAÇÃO COM O BRASIL. 2018.

MARTINE, George. A globalização inacabada: migrações internacionais e pobreza no século 21. São Paulo em perspectiva, v. 19, n. 3, p. 3-22, 2005.

NETO, H. P. Tendências internacionais em políticas migratórias e o caso brasileiro. In: Migrações na Pan-Amazônia. São Paulo: HUCITEC, 2012, pp. 289-299

SILVA, Sidney Antonio da (Ed.). Migrações na Pan-Amazônia: fluxos, fronteiras e processos socioculturais. Hucitec Editora, 2012

SCHWARCZ, Lilia Moritz. O espetáculo das raças: cientistas, instituições e questão racial no Brasil do século XIX. Editora Companhia das Letras, 1993.

XAVIER, Fernando César Costa. Migrações internacionais na Amazônia brasileira: impactos na política migratória e na política externa. 2012. 